\title{
A gestão dos conflitos e seus efeitos políticos: Apontamentos de pesquisa sobre mineração no Espinhaço, Minas Gerais
}

Managing conflicts and their political effects: some considerations about mining in Espinhaço, Minas Gerais

\section{Raquel Oliveira}

Brasil. Universidade Federal de Minas Gerais. Professora do Departamento de Sociologia e pesquisadora do Grupo de Estudos em Temáticas Ambientais. ID ORCID: https://orcid.org/00oo0003-1191-4695. E-mail: raqueloliveira2002@gmail.com. Colaboração: pesquisa bibliográfica, pesquisa empírica em Morro do Pilar (MG) e Linhares (ES), redação e revisão.

\section{Marcos Cristiano Zucarelli}

Brasil. Universidade Federal de Minas Gerais. Doutor em Antropologia. Pesquisador colaborador do Grupo de Estudos em Temáticas Ambientais. ID ORCID: https://orcid.org/0000-0003-0664-730X. E-mail:mczucarelli@gmail.com. Colaboração:pesquisa bibliográfica, pesquisa empírica em Conceição do Mato Dentro (MG), redação e revisão.

\section{Resumo}

A partir do acompanhamento de reuniões deliberativas do Conselho de Política Ambiental de Minas Gerais (Copam), o artigo examina as estratégias corporativas de gestão da crítica em um cenário de expansão da atividade minerária e multiplicação dos conflitos. O intuito é problematizar as respostas corporativas às críticas e seus efeitos sobre a ação política opositiva aos projetos minerários.

Palavras-chave: Conflitos, Mineração, Licenciamento Ambiental.

Recebido em 27 de fevereiro de 2020. Avaliador A: 16 de abril de 2020 


\section{Abstract}

Based on analysis of deliberative meetings of the Council of Environmental Policy of Minas Gerais (COPAM), this article examines corporate strategies used for managing criticism in a scenario of expansion of mining activity and growing conflicts, analyzing corporate strategies for dealing with criticisms and their effects on the political action of those opposed to mining projects.

Keywords: Conflicts, Mining, Environmental Licensing.

\section{INTRODUÇÃO}

Chegamos ao local da reunião na cidade de Diamantina, Minas Gerais. Há alguma movimentação de pessoas na entrada do prédio. Na pauta para a apreciação e deliberação dos conselheiros constam ambos os processos de licenciamento da Manabi e da Anglo American. Subimos as escadas. O hall está cheio. Há pequenas rodas de conversas dispersas entre conselheiros, técnicos do órgão ambiental, consultores e representantes das empresas. Tentamos localizar um dos possíveis conselheiros "aliados", pois também é nosso momento de fazer o "lobby" oposto. Conversamos rapidamente de forma discreta e interrogamos sobre seu conhecimento e posicionamento quanto ao processo da Manabi. Ele enfatiza que não houve tempo suficiente para ler os documentos e nós argumentamos sobre a má-qualidade dos estudos socioambientais apresentados. Cumprimentamos também o procurador federal que já se fazia presente e trazia uma Recomendação dirigida ao Conselho. Em seguida, buscamos um lugar na enorme fila que se formou para acesso à sala de reunião. O lugar já está tomado pelos consultores e representantes das empresas. Os enfrentamentos se iniciam na disputa pelo controle do espaço, pela chance de entrar na sala, pequena demais para acolher o público e pela possibilidade de conseguir um lugar para assentar-se. Os ônibus trazendo os moradores de Morro do Pilar chegam ao local. Os veículos padronizados sugerem que foram disponibilizados pela empresa ou pela prefeitura municipal. Os moradores recém-chegados também disputam seu acesso à sala. Há um clima de tensão. Os técnicos restringem ainda mais a entrada dispondo em sua frente uma mesa para o registro das inscrições daqueles que desejam se pronunciar. Um sujeito trajando o uniforme da 
Manabi coloca-se ao lado da mesa de inscrições e inicia uma espécie de controle e triagem, bloqueando com o corpo o fluxo direto das pessoas à sala, enquanto claramente orienta os moradores de Morro do Pilar a se inscreverem para sua manifestação - espera-se favorável - ao projeto. A tensão aumenta porque o fim da fila pressiona o acesso já obstruído à sala. Alguns moradores de Morro do Pilar traziam faixas, declarando seu apoio ao empreendimento. Na porta do prédio, estudantes e representantes dos movimentos sociais distribuem panfletos contestando o projeto Manabi e são hostilizados por um funcionário da administração municipal de Morro do Pilar. Ele fotografa aqueles que entregam os panfletos e ofensivamente aborda os estudantes. A reunião tem início com sua formalidade ritual, os conselheiros tomam seus respectivos lugares, assim como os técnicos. Boa parte das cadeiras está ocupada pelos consultores. P. e L., atingidos pelo projeto Anglo American conseguem adentrar a sala carregando uma caixa térmica de isopor. Os demais atingidos pelo projeto Minas-Rio organizam os materiais preparados e trazidos, distribuem cartões verdes e vermelhos para a manifestação e abrem suas faixas, banners e cartazes, contendo fotografias que denunciam os efeitos da instalação da Anglo American. O Secretário de Meio Ambiente do Estado de Minas Gerais está presente, fato raro nas reuniões deliberativas e, após o momento solene de abertura, pede a palavra. Seu pronunciamento é rápido e sua posição explícita quando afirma que a cidade de "Morro do Pilar padece na lama e que Conceição do Mato Dentro padeceu com o atoleiro". Para o Secretário, ambos os processos estão aptos para serem votados e em suas palavras: "darei condições para os senhores [conselheiros] aferir aquilo que vier". O primeiro processo a ser debatido é o caso da Manabi. Alguns representantes de nosso grupo de pesquisa se pronunciam, acentuando os impactos que não foram devidamente dimensionados e os efeitos cumulativos e sinérgicos sobre a região já bastante afetada devido ao projeto Minas-Rio. Enquanto alguns colegas falam ao microfone são hostilizados pelos moradores de Morro do Pilar. Um cronômetro controla o tempo destinado a cada uma das intervenções, todos têm apenas três minutos para a fala. Após nossa intervenção em que ressaltamos a existência de comunidades tradicionais possivelmente portadoras de direitos diferenciados, mas não devidamente contempladas nos estudos apresentados, alguns moradores gritam: "Lá não tem quilombo!" e "Vai você viver lá. Outros pesquisadores mencionam os possíveis impactos sobre as áreas de coleta das fibras de indaiá e taquaraçu essenciais para o fabrico das tradicionais esteiras, chapéus e outros objetos produzidos artesanalmente pelas trançadeiras e chapeleiras do município. Minutos depois pronuncia-se um senhor que se apresenta como morador de Facadinho, uma das comunidades mencionadas. Ele ressalta que a "comunidade quer a 
Manabi para trazer empregos". Em seguida outros pronunciamentos semelhantes, incluindo a manifestação do pastor que se apresenta como liderança e representante da comunidade de Carioca e afirma enfaticamente: "Que a Manabi seja bem-vinda em nossa comunidade". Seguem-se outras intervenções e alguns conselheiros começam a se manifestar. O conselheiro aliado, sublinha a deficiência dos estudos, as promessas realizadas frequentemente pelos empreendedores e os efeitos nefastos causados invariavelmente pelos projetos de desenvolvimento. Em seguida, o conselheiro representante do Ministério Público Estadual apresenta uma série de questionamentos de ordem ambiental levantados em estudos técnicos independentes solicitados pela própria instituição. Há polarização nas manifestações dos conselheiros, quando a Federação das Indústrias do Estado de Minas Gerais se pronuncia declarando seu apoio ao projeto antes que sejam solicitados os respectivos votos do conselho. Ânimos exaltados até que o representante do Ministério Público Estadual solicita vistas ao processo. Os moradores de Morro do Pilar se exaltam, mas toda a discussão está suspensa. O presidente da mesa introduz o próximo ponto da pauta: o empreendimento Minas-Rio. O representante do Ministério Público inicia uma série de questionamentos, desde a indisponibilidade de informações técnicas para a composição do juízo dos conselheiros, até o descumprimento de medidas anteriormente acordadas como a realização de visitas "in loco" para a oitiva das comunidades, fato que não ocorrera. Os técnicos da unidade são chamados a prestar esclarecimentos e a apresentar suas avaliações aos conselheiros. As fotos e banner trazidos pelos moradores mostram a transformação dos córregos. O técnico responsável inicia sua apresentação e análise dos dados acerca da qualidade da água. Suas colocações parecem retratar o problema como algo temporário, resultante de um mero carreamento de sedimentos que teria alterado apenas fatores de menor importância como a turbidez da água. Os atingidos pelo projeto se exaltam. Escutamos uma moradora que grita no fundo da sala: "Então vai lá beber essa água”. P. se levanta, ele carrega o isopor e o leva para o centro da mesa, o presidente ainda não havia franqueado o espaço para as manifestações dos presentes. Ele abre a caixa e é auxiliado por L. Da caixa eles retiram garrafas plásticas contendo amostras de água do Córrego Passa-Sete e diversos exemplares dos peixes mortos que foram coletados naquele curso d'água. As garrafas são distribuídas aos conselheiros e os peixes dispostos sobre a mesa do conselho para que eles vejam. P. e os demais são eloquentes em suas denúncias apresentadas como impedimentos à concessão da Licença de Operação. A polícia militar é chamada. Entendendo que havia divergências e receando uma confusão maior, o conselheiro representante do Ministério Público faz o pedido de vistas do processo. A reunião estava encerrada (MINAS GERAIS, 18 set. 2014). 
Dois meses depois o processo da Manabi está novamente em pauta no conselho, retornamos a Diamantina. A reunião fora transferida para outro local, agora um amplo espaço de eventos, onde são celebradas festas de casamentos e aniversários na cidade. Todo o público está mais disperso entre as cadeiras ordenadas em fileiras frontalmente à mesa dos conselheiros que agora se encontra separada e protegida por um cordão de isolamento. É vedado o acesso do público aos conselheiros. Após os acontecimentos da última reunião, a representante da Federação das Indústrias solicitou medidas de proteção, argumentando temer por sua segurança. Há apenas um acesso à mesa guardado por policiais militares, o microfone para as manifestações encontra-se fora do cordão do isolamento. Todo o local está guarnecido com a presença de soldados. Os moradores de Morro do Pilar chegam ao local, eles trazem novamente faixas de apoio e portam no peito pequenos laços de fibra de taquaraçu. Tentamos nos aproximar de uma senhora para perguntar-lhe sobre o significado do pequeno laço, mas somos repreendidos por um morador mais jovem que intervém, impede nossa conversa, retira a senhora do local e a coloca em outro assento. Nossa intervenção é solicitada pelo próprio conselheiro representante do Ministério Público Estadual e endossamos as posições já anunciadas anteriormente acerca do caráter deficiente dos estudos apresentados. Ao final, somos hostilizados com vaias e cartões vermelhos pelos moradores de Morro do Pilar, novamente trazidos nos ônibus fretados pela Manabi. Dessa vez, os apoiadores do projeto portam e utilizam os cartões verde e vermelho, mimetizando uma das estratégias empregadas anteriormente pelos atingidos do Minas-Rio (MINAS GERAIS, 6 nov. 2014).

Este relato é fruto de nossa atuação como integrantes do Grupo de Estudos em Temáticas Ambientais $\left(\right.$ Gesta) ${ }^{1}$ da Universidade Federal de Minas Gerais (UFMG), o qual realizou assessoria às mobilizações de atingidos dos projetos Minas-Rio e Manabi. A partir das atividades de pesquisa

\footnotetext{
Trata-se de um núcleo acadêmico dedicado a atividades de ensino, pesquisa e extensão associadas à compreensão dos conflitos ambientais. A atuação do Gesta tem privilegiado a interface entre pesquisa e extensão, buscando refletir sobre os efeitos sociais de grandes projetos e seus processos hegemônicos de apropriação do território, ao mesmo tempo que procura auxiliar, mediante demanda das comunidades afetadas, suas mobilizações com vistas ao controle social dos processos de licenciamento ambiental. Agradecemos às agências de fomento Conselho Nacional de Desenvolvimento Científico e Tecnológico (CNPq), Fundação de Amparo à Pesquisa do Estado de Minas Gerais (Fapemig) e Fundação de Amparo à Pesquisa e Inovação do Espírito Santo (Fapes) -, pelo apoio aos projetos de pesquisas desenvolvidos, eà Coordenação de Aperfeiçoamento de Pessoal de Nível Superior (Capes), pela bolsa de doutorado concedida a Marcos Cristiano Zucarelli.
} 
e extensão conduzidas pelo grupo, o objetivo é tomar os eventos descritos como ponto de partida para refletir sobre as correlações de força e as estratégias levadas a cabo pelos agentes corporativos para a implantação de empreendimentos minerários na região da Serra do Espinhaço, Minas Gerais. Os acontecimentos de duas reuniões sucessivas da unidade regional colegiada (URC) do Conselho de Política Ambiental de Minas Gerais (Copam) revelam dois pontos fundamentais de nossa análise, a saber, (1) a produção do consentimento e das redes locais de aliança no caso do projeto Manabi e (2) as formas de gestão da crítica desenvolvidas no caso Minas-Rio, que buscam a marginalização e o ostracismo das iniciativas locais de resistência, criando a necessidade de esforços contínuos de mobilização e denúncia por parte dos atingidos.

Iniciamos com uma breve exposição sobre os respectivos projetos. O projeto Minas-Rio Mineração e Logística Ltda., do conglomerado britânico Anglo American, é constituído por três grandes estruturas associadas: (1) uma mina de exploração de ferro a céu aberto em Conceição do Mato Dentro, Minas Gerais; (2) um complexo portuário no litoral norte do estado do Rio de Janeiro; e (3) um mineroduto de 529 quilômetros de extensão que atravessa 33 municípios desses dois estados. Mesmo integradas, tais estruturas passaram por licenciamentos em três esferas distintas. $\mathrm{O}$ mineroduto foi avaliado pelo órgão federal, o Instituto Brasileiro do Meio Ambiente e dos Recursos Naturais Renováveis (Ibama); o Porto do Açu, localizado em São João da Barra (RJ), foi licenciado pelo órgão ambiental do Rio de Janeiro, o Instituto Estadual do Ambiente (Inea); já o licenciamento da mina e das estruturas adjacentes foi avaliado pela Secretaria de Estado de Meio Ambiente e Desenvolvimento Sustentável de Minas Gerais (Semad). A fragmentação do licenciamento é uma estratégia recorrente que permite o ocultamento das afetações sobre os territórios, configurando uma "geografia ficcional do empreendimento" (SANTOS, 2014, p. 155).

Desde o início do licenciamento, em 2007, as famílias atingidas organizaram uma resistência crescente, que se articulou com iniciativas diversas junto às entidades científicas, não governamentais, movimentos sociais e órgãos da Justiça. Diante 
da iminência da judicialização dos conflitos decorrentes da implantação do projeto, foi criada, por iniciativa do Ministério Público do Estado de Minas Gerais (MPMG), a Rede de Acompanhamento Socioambiental (Reasa) cujo objetivo era instituir um espaço de discussão entre os atores envolvidos na implantação do projeto MinasRio. Planejada como um espaço de diálogo mediado pelo próprio MPMG, a Reasa foi instituída como fórum para a resolução negociada dos conflitos derivados do empreendimento. No entanto, as questões elencadas pelas comunidades, embora debatidas, nunca constituíram empecilho à concessão de licenças ambientais. Em 2019, o projeto obteve sua terceira licença de expansão.

Já o empreendimento Manabi consiste na implantação da infraestrutura de extração de minério de ferro, um mineroduto, além de um terminal portuário, designado Porto Norte Capixaba. ${ }^{2}$ As cavas a céu aberto têm sua instalação prevista no município de Morro do Pilar, vizinho de Conceição do Mato Dentro. O projeto ainda se encontra em licenciamento, tendo sido emitida apenas a licença prévia estadual para as cavas e demais estruturas associadas à planta extrativa. O mineroduto está sob análise do órgão ambiental federal, assim, como o porto. Ao longo de sua extensão, o projeto Manabi colide com os territórios de comunidades tradicionais.

A partir da reflexão sobre esses dois projetos, que atravessam momentos distintos do licenciamento, intentamos examinar os efeitos políticos da administração da crítica levada a cabo tanto por atores corporativos quanto por agentes públicos.

\section{O MINAS-RIO E SUAS NOVAS FORMAS DE REGULAÇÃO DO CONFLITO: CONTROLE E MARGINALIZAÇÃO DA RESISTÊNCIA}

O pedido para obtenção da licença prévia da mina do projeto MinasRio foi formalizado junto ao órgão ambiental mineiro em setembro de 2007.

A exploração das cavas teve a licença prévia concedida pela Semad em novembro de 2014. O mineroduto e o porto tiveram seu licenciamento prévio arquivados pelo Ibama em abril de 2016. 
Em março de 2008 ocorreu a audiência pública, ocasião em que os moradores da região manifestaram suas posições e entregaram documentos contestadores ao juízo de viabilidade socioambiental do empreendimento, situado no interior da Reserva da Biosfera da Serra do Espinhaço. O parecer único emitido pelo Sistema Estadual de Meio Ambiente (Sisema) também ressaltava a importância ambiental da área, além de uma série de falhas e insuficiências na análise dos impactos sociais e ambientais do licenciamento (MINAS GERAIS, 2008).

Não obstante, a conclusão do parecer do órgão técnico foi pela viabilidade ambiental do empreendimento. Assim, a licença prévia foi concedida pelo Copam, em dezembro de 2008, com centenas de condicionantes, que foram postergadas para a fase seguinte do licenciamento, a despeito da ausência de informações cruciais à própria formação do juízo de viabilidade ambiental do empreendimento (MINAS GERAIS; ANGLO FERROUS MINAS-RIO MINERAÇÃO, 2008), em especial, o desconhecimento do universo das famílias que seriam atingidas.

A continuidade do projeto evidenciou, ao longo dos anos, a magnitude dos efeitos negligenciados pela empresa e pelo Estado. Em vistoria realizada pela analista pericial em antropologia do Ministério Público Federal (MPF), em novembro de 2009, constatou-se que duas comunidades que se encontravam no limiar da zona de interseção entre os licenciamentos das obras do mineroduto e da mina a céu aberto estavam desamparadas pelos diferentes órgãos ambientais responsáveis. A peça técnica relatava o comprometimento dos modos de vida dessas famílias, devido a transformações como: proibição de acessos costumeiramente utilizados, ruídos, suspensão de material particulado e alterações na qualidade e volume dos recursos hídricos (BRASIL, 2009). Mesmo com os problemas denunciados pelos atingidos e apontados pelas vistorias técnicas, o prosseguimento do licenciamento da mina se deu através de uma nova fragmentação, que desdobrou a licença de instalação (LI) em duas fases distintas, "LI Fase 1" 
e "LI Fase 2". ${ }^{3}$ Essa medida possibilitou que as condicionantes atendidas fossem associadas à etapa $1 \mathrm{e}$ aquelas não executadas fossem vinculadas à etapa 2 , sendo seu cumprimento efetivamente postergado sem prejuízo ao andamento do projeto que recebeu autorização para iniciar suas instalações.

Com as intervenções no local, os anos de 2009 e 2010 se caracterizaram pelo agravamento do quadro socioambiental em Conceição do Mato Dentro, devido à indefinição da situação dos atingidos e aos efeitos provocados pelas obras de instalação da mina, bem como ao avanço do mineroduto. Nesse contexto, a Secretaria Estadual de Meio Ambiente (Semad) convocou diversos órgãos, instâncias de fiscalização e sociedade civil a um esforço para solucionar os problemas do licenciamento. Várias medidas decorreram desse movimento, como a exigência, transformada em condicionante da LI fase 1 para a fase 2 (concedida em dezembro de 2010), de observar parâmetros e critérios mínimos para o reassentamento das famílias atingidas. ${ }^{4}$ Também foi incluída nesta etapa avançada do licenciamento a necessidade da elaboração de um cadastro de atingidos. Em março de 2010, os órgãos responsáveis pelo licenciamento nos âmbitos estadual e federal foram instados a fazer uma vistoria conjunta das obras. A situação das famílias que se encontravam no limiar das áreas de licenciamento do Ibama e do Sisema se agravara e, conforme o relatório do MPF:

[...] as famílias vem [sic] sendo paulatinamente inviabilizadas em seus locais de moradia, há meses, sem que nenhuma medida, por parte de qualquer órgão fiscalizador, seja do Estado, seja da União, tenha

3 Essa medida não possui fundamentação ou previsão no marco regulatório ambiental (ZHOURI, 2014, p. 125). Segundo Becker e Pereira (2011, p. 245-246), a distribuição das atividades entre as duas fases seguia a seguinte organização:

a) fase 1 - Mina: resgate de flora (ficando para a fase 2 a supressão da vegetação e decapeamento do solo); pilha de estéril, Centro de Referência Cultural e Ambiental, Estação de Bombas do Rio do Peixe: abertura de acessos; terraplenagem, aterros, cortes e fundações (obras com balanço de massa estimado em 6 milhões de metros cúbicos de terra); edificação do canteiro de obras, unidades operacionais, almoxarifados e alojamentos; aterro sanitário; dique de contenção de finos;

b) fase 2 - Edificação da unidade de beneficiamento, construção da barragem de rejeitos e da adutora para condução da água captada no rio do Peixe.

4 A referência utilizada nesse caso foi o Termo de Ajustamento de Conduta (TAC) elaborado durante o licenciamento da usina hidrelétrica de Irapé. Este documento é considerado no estado de Minas Gerais uma importante diretriz de negociação fundiária, relocação e reassentamento de comunidades. Para uma reflexão crítica sobre a efetividade do TAC de Irapé, ver Zucarelli (2011). 
sido efetivada, para impedir que tal situação se perpetuasse; no atual momento, já desesperadas com sua situação, essas famílias começam a manifestar urgência em abandonarem [sic] seus lugares, negociando seus patrimônios sem a tranquilidade necessária para assegurarem [sic] que suas condições de vida sejam recriadas em outro lugar (BRASIL, 2010, p. 15).

O Ibama desconsiderou, no curso do licenciamento, a existência de comunidades tradicionais situadas na área afetada pela implantação das estruturas que compõem o ponto de partida do mineroduto (BRASIL, 2009, p. 25-29). O Sisema, neste mesmo contexto, atribuiu única e exclusivamente a responsabilidade ao Ibama, para que o órgão intercedesse junto ao empreendedor e cobrasse medidas mitigadoras para sanar os impactos identificados. Ao longo do ano de 2010, formou-se uma prévia Comissão de Atingidos e, a partir da intervenção do MPMG e da Defensoria Pública, firmaram-se acordos com o empreendedor para assegurar, em tese, parâmetros mínimos de relocação. Neste ínterim, a empresa Anglo American anunciou, em 2011, suas ações como "modelar", a partir do "Programa de Negociação Fundiária" criado para atender os "80 proprietários de terrenos" nas comunidades de Ferrugem/Sapo, Água Santa e Mumbuca (PROJETO..., 2011).

Conforme demonstram Becker e Pereira (2011, p. 246-248), enquanto os impactos se agravavam, atingindo um contingente populacional cada vez mais amplo, a empresa acionava dispositivos burocráticos e técnicos para evitar o reconhecimento dos danos e dos atingidos em sua totalidade.

Com a implantação da infraestrutura para exploração da mina, ampliaram-se os efeitos socioambientais decorrentes do empreendimento, os quais foram sistematicamente elididos, uma vez que não haviam sido prognosticados pelos “técnicos responsáveis" em nenhuma das instâncias de licenciamento. Esta "falha" no prognóstico existente nos estudos de impacto ambiental pode ser explicada pela adoção de uma definição extremamente restritiva para o reconhecimento do universo sociocultural afetado, limitando-o à área necessária à instalação das principais estruturas do empreendimento. Baseando-se neste critério, a empresa anunciou o número de " 80 proprietários". 
Contudo, a URC Jequitinhonha determinou que a mineradora custeasse um novo laudo a ser realizado por empresa independente, indicada pela Comissão de Atingidos, para uma melhor caracterização da área diretamente afetada (ADA) e da área de influência direta (AID) do complexo minerário. O novo estudo, um diagnóstico socioeconômico realizado pela Diversus Consultores Associados Ltda., foi finalizado em agosto de 2011 (quase um ano após a concessão da LI fase 2) e constatou não somente duas comunidades, conforme apresentado pelo estudo de impacto ambiental (EIA)/ relatório de impacto ambiental (Rima), mas um universo de mais de quatrocentos domicílios distribuídos por 22 comunidades afetadas.

Entretanto, nos embates travados entre as licenças de instalação (fases 1 e 2) sobre a delimitação do universo populacional atingido, optou-se por um recorte restritivo, implícito à nova categoria acionada de "atingido emergencial". Sob a justificativa de atender urgentemente às famílias que ficaram reféns das obras iniciais do mineroduto e que, na verdade, se sobrepunham ao local das instalações de infraestrutura da mina, o licenciamento passou a operar com uma nova engrenagem de fragmentação, desta vez, do conjunto dos atingidos (BECKER; PEREIRA, 2011; DIVERSUS, 2011).

No ano de 2012 houve uma audiência pública, coordenada pelo MPMG, ocasião em que os atingidos questionaram os reassentamentos e os contratos de venda de terras feitos junto à empresa. Denunciaram ainda a "contaminação das nascentes de água, envenenamento da criação, fragmentação e perda de coesão de comunidades e famílias, invasão de terras e retirada sem autorização de equipamentos como porteiras e cercas, usados para delimitar as propriedades" (FURBINO, 2012). Um mês após a audiência, três recomendações legais, emitidas de forma conjunta pelo MPMG, MPF e Defensoria Pública, exigiram da Anglo American medidas destinadas a fazer cessar as violações de direitos da população atingida.

Como desdobramento, foi criada a Reasa, proposta em reunião realizada em maio de 2012, na comunidade de Jassém, pela Coordenadoria de Inclusão e Mobilização Social (Cimos), órgão auxiliar da atividade funcional do MPMG. A ideia era que essa rede se reunisse mensalmente e acompanhasse a trajetória 
do processo de licenciamento e instalação do projeto Minas-Rio. Esta rede seria formada, a priori, pelos secretários de Meio Ambiente dos três municípios envolvidos e por representantes de cada uma das comunidades atingidas; dos Conselhos Municipais de Meio Ambiente (Codema) e Desenvolvimento Rural Sustentável (CMDRS); da Semad; dos grupos de pesquisa; do MPMG, do MPF e da Defensoria Pública (GESTA, 2019). Institucionalmente, a Reasa é definida como uma rede

[...] criada a partir da necessidade de se acompanhar responsabilidades e impactos socioambientais de empreendimento minerário em Conceição do Mato Dentro e região. Essa estratégia de atuação ministerial proativa e resolutiva para além de evitar a judicialização e contribuir para a pacificação social, pretende-se seja utilizada como paradigma em outras regiões com o intuito de minorar e prevenir violações a Direitos Fundamentais, decorrentes de grandes empreendimentos (MINAS GERAIS, 2012, grifo nosso).

$\mathrm{Na}$ Reasa, o posicionamento e a estratégia da empresa foram ligeiramente modificados. Por um lado, o conceito de "atingido emergencial" permitia que ela promovesse gestos simbólicos de reparação, mantendo simultaneamente intenso controle sobre a definição dos danos e do universo das reparações; por outro lado, a inserção no espaço "dialógico" e "participativo" da Reasa revelava o engajamento necessário com a resistência, oferecendo-lhe perspectivas para "encontrar e educar seus críticos" (BENSON; KIRSCH, 2010). A primeira reunião da Reasa ocorreu em São José do Arruda, município de Alvorada de Minas, em 17 de junho de 2012. A partir de então, deu-se uma sistemática de reuniões mensais em diferentes comunidades até o ano de 2014.

Entretanto, as expectativas de um arrefecimento das críticas a partir dos encontros da Reasa se viram frustradas na medida em que a participação da empresa nessas reuniões tornou-se em si mesmo um ponto de tensão, haja vista não contribuir com esclarecimentos suficientes às denúncias e às demandas dos atingidos e, consequentemente, não facilitar a resolução dos problemas relatados. Dessa maneira, a presença apenas figurativa do empreendedor 
foi criticada nas reuniões 5 . O estabelecimento destes espaços e a participação dos atingidos sugere certa relação contraditória, pois, de um lado, há a idealização de um Estado democrático e de seus projetos de desenvolvimento e, de outro, a vivência dessas práticas nos locais pelas pessoas que experimentam a expropriação. Isso "cria a possibilidade de políticas de resistência, as quais combinam conflito com colaboração, criticando o Estado mesmo quando se engajam no diálogo e na negociação com ele" (BAVISKAR, 2001, p. 1-2).

A despeito de todos os questionamentos colocados ao longo do processo de licenciamento, inclusive relativos à indefinição do universo dos atingidos pelo projeto de mineração, o Copam pautou o estudo realizado pela consultoria Diversus após dois anos de sua conclusão. Todavia, foi incluído também na pauta um contra parecer recém-contratado pela Anglo American. Nesse documento, a análise valeu-se de dados secundários e diretrizes normativas, sem qualquer avaliação in loco, ao contrário da metodologia adotada pela Diversus, que realizou um extenso trabalho de campo nas comunidades locais. Como consequência, a conclusão do novo estudo contratado reduzia numericamente os atingidos e qualificava os impactos apontados pela Diversus como "impactos supostos" (FERREIRA ROCHA, 2013).

Desse modo, uma das modalidades de gestão corporativa da crítica empregada pela Anglo American foi a negação aberta da validade das denúncias (BENSON; KIRSCH, 2010), incluindo o recurso à contratação de um contraparecer destinado a questionar e restringir a definição de "atingido" a ser reconhecida e operacionalizada no âmbito do licenciamento. O posicionamento apresentado foi a negação ou limitação dos “impactos", reduzindo a responsabilidade do empreendedor em relação aos efeitos do projeto, a partir de esforços corporativos de "proliferação da dúvida" ou "manufatura da incerteza" (BENSON; KIRSCH, 2010).

Certamente, a tentativa de negação da crítica incitou em P. e L., atingidos protagonistas da cena etnográfica narrada no início deste artigo, a iniciativa de levar, às vésperas da concessão da licença de operação, amostras da água e dos

\footnotetext{
5 Para outros detalhes sobre a dinâmica das reuniões da Reasa e uma análise desses encontros, ver Prates
} (2014); e Pereira, Becker e Wildhagen (2013). 
peixes mortos para provar que os efeitos eram reais, consequências concretas das ações do empreendimento ao longo de oito anos.

Apesar de pautados, inclusive em outras reuniões ordinárias, os estudos mencionados nem chegaram a ser avaliados pelos conselheiros da URC Jequitinhonha. Sob a interpretação do órgão ambiental mineiro, a principal demanda, qual seja, a elaboração de um cadastro com todas as famílias atingidas, ainda não havia sido realizada. Nesse sentido, deliberou-se que a Diversus deveria retornar a campo para efetuar o "cadastramento" das famílias. Apesar do primeiro estudo da Diversus demonstrar diferentes efeitos nas inúmeras comunidades visitadas, faltava, segundo o órgão ambiental, um cadastro com os nomes daqueles atingidos que deveriam ser contemplados pelas medidas de reassentamento, compensação e/ou mitigação. Multiplicada a dúvida, investia-se na replicação de estudos e na protelação do reconhecimento dos atingidos.

Veena Das e Deborah Poole (2008) podem auxiliar nessa tentativa de compreensão da conflituosa relação entre Estado e populações objeto de intervenções dos programas de desenvolvimento. Quando as autoras propõem refletir sobre o Estado e suas margens, pontuam três conceptualizações de margem. Na primeira, margens são entendidas como periferias nas quais seriam utilizadas tecnologias de poder para "administrar" ou "pacificar" as populações "periféricas", utilizando-se tanto a força legitimada quanto uma pedagogia da conversão destinada a transformar os "sujeitos ingovernáveis" em sujeitos legais do estado. Esta primeira definição nos diz muito sobre a atuação do MPMG quando estabelece um espaço formal de discussão e resolução de conflitos no âmbito do licenciamento ambiental. A "pacificação social" (MINAS GERAIS, 2012) é um dos objetivos da criação da Reasa, conforme citado anteriormente. Assim, as aspirações de certos grupos de resistência ao se inscreverem na formatação do diálogo legal, "convergem com o zelo disciplinador do Estado e seu interesse em criar espaços legíveis e sujeitos dóceis" (BAVISKAR, 2003, p. 90).

A segunda definição de Das e Poole (2008) para margem pode ser tratada como uma consequência da primeira, uma vez que o objetivo é identificar os sujeitos como legíveis ou ilegíveis. O sujeito social que de alguma forma está sendo afetado pelas obras do projeto de desenvolvimento somente poderá 
"participar" do processo depois de identificado e devidamente legitimado, trata-se, portanto, da definição autorizada de "atingido". Após a identificação, os atingidos saem da condição "periférica" e se tornam "aptos" a "participar" das instâncias de licenciamento e/ou das esferas de mediação/ resolução dos conflitos. Os embates pela definição de quem seria considerado atingido e a necessidade de realizar um cadastro destes são elucidativos para este caso.

A terceira e última definição das autoras, refere-se à margem como um espaço entre os corpos, a lei e a disciplina, lugar onde o poder soberano do Estado afeta não somente os territórios, mas também os corpos dos sujeitos. Nesse caso, aqueles deixados à margem da definição autorizada de "atingido" permanecem sofrendo de forma intensa, sensível e tangível a efetividade dos "impactos" representada pelo comprometimento das nascentes, pela degradação dos córregos e pela perda dos rebanhos, hortas e todo o horizonte de saberes e estratégicas historicamente desenvolvidos na relação com um ambiente e com uma paisagem que já não existem.

Para as autoras (DAS; POOLE, 2008), as formas de ilegibilidade, pertencimento parcial e desordem que parecem constituir as margens do Estado, na verdade, constituem condição necessária do aparente ordenamento político e regulador de um Estado central e burocrático. Neste sentido, a Reasa pode ser entendida como um espaço construído conforme o modelo de governança e de resolução negociada de conflitos que institui o diálogo em alternativa à via da judicialização, obstando importantes vias de resistência e contestação que pudessem contar com o auxílio da justiça (ZUCARELLI, 2018).

Conforme a análise do caso Minas-Rio, se os acordos extrajudiciais podem configurar formas de garantir a regulação e a continuidade do empreendimento, a "participação" dos grupos subalternos e sua capacidade de defender seus direitos se vê minada pela primazia do diálogo e da disposição necessária ao entendimento mútuo das partes. Operacionalizando uma definição estreita, mas autorizada, de atingido, a empresa recorre ao terreno do "desenvolvimento sustentável" e da "responsabilidade social corporativa". Ao fazê-lo, promove o ideal de consenso e harmonia, enquanto marginaliza aqueles não contemplados pela contabilidade dos "atingidos" autorizados. Os ilegíveis e não contáveis, no 
entanto, permanecem insistindo em ações de denúncia e mobilização enquanto seguem retratados como minorias recalcitrantes.

\section{ESTRATÉGIAS CORPORATIVAS E INVESTIMENTOS ANTECIPATÓRIOS: A DOMESTICAÇÃO DO CONFLITO E A PRODUÇÃO DE ALIANÇAS E TRINCHEIRAS LOCAIS EM DEFESA DO DESENVOLVIMENTO}

Perambulando calmamente pelas ruas de Regência, no Espírito Santo, é possível encontrar indícios dispersos de uma oposição ao projeto portuário da Manabi. Em alguns muros, pichações registram o slogan, também veiculado via web, “Fora Manabi”. A vila de Regência apresenta significativo movimento turístico proporcionado pelas instalações do projeto Tamar e por fatores naturais que fazem daquela área um ponto atrativo para a prática de surf, além da Reserva Biológica de Comboios. Com dimensões diminutas, Regência apresenta, no entanto, uma considerável oferta de pousadas, um camping e casas e suítes disponíveis para locação para temporadas. A rotina da vila gira em torno da pesca e do turismo e é na conjugação dessas atividades, articuladas ao assalariamento temporário junto às empresas de pesquisa e prospecção de petróleo e gás, que os pescadores mantêm suas estratégias de reprodução social.

Na pacata vila de Regência se justapõem moradias humildes, pousadas e casas de veraneio. Há uma pequena estrutura construída recentemente para receber e atracar as embarcações de pesca, uma praça com igreja, casa de congo e a cúpula do antigo farol, há pouco tempo restaurada com patrocínio da Manabi. Embora algumas mensagens de rejeição ao porto estejam estampadas em muros, breves conversas junto aos pescadores revelam que tal oposição é organizada pela iniciativa de surfistas, veranistas e turistas que frequentam regularmente o balneário. Em contraste, os pescadores e suas lideranças declaram seu apoio quase irrestrito ao projeto, conforme ressaltou B., pescador: "Você me pergunta o que eu acho da Manabi? Eu digo: que ela viesse ontem!'” Por sua vez, Z., liderança informal na pesca, destaca em relação 
aos acordos costurados entre a empresa e a Associação de Pescadores: “Tá tudo fechado, eles [associação] já aceitaram”, e continua, ressaltando a importância do empreendimento para a geração de empregos na localidade, "eu tenho certeza que se eles precisarem pra trabalho no mar, eles vão me chamar, vai ser muito bom pra gente". Na localidade de Degredo, onde discursos similares se repetem, uma liderança enfatizou a necessidade de postos de trabalho na comunidade, especialmente para os mais jovens, "meus filhos podiam tá tudo aqui, mas tá tudo esparramado"6.

O que chama a atenção em tais posicionamentos é a aberta defesa do empreendimento por parte de um grupo que depende dos recursos pesqueiros, os quais serão significativamente afetados pelo empreendimento. Contudo, o apoio ao empreendimento Manabi se destaca também entre os habitantes do município de Morro do Pilar, em Minas Gerais, onde está prevista a abertura das cavas. Nas audiências ocorridas para apreciação e deliberação da licença prévia do projeto minerário, os participantes demonstraram seu apoio com faixas, aplausos e manifestações, como ilustra o seguinte fragmento:

Mas agora Morro do Pilar está tendo uma grande oportunidade; oportunidade de desenvolvimento, de crescer, de poder ter busca de emprego, de podermos crescer, vamos juntos envelhecer com a nossa família, coisa que é difícil acontecer. Então, Morro do Pilar está ciente de quem é a Manabi, do que a Manabi faz, do que ela pode ou não pode fazer; Morro do Pilar apoia Manabi, Morro do Pilar quer a Manabi e a juventude de Morro do Pilar está com a Manabi (MINAS GERAIS, 2014).

Nessa medida, a investigação sobre o licenciamento do projeto Manabi apontou para a importância de se examinar a construção social desse consentimento e apoio. Durante as pesquisas de campo no município de Morro do Pilar, em 2014, presenciamos situações e relatos que evidenciam um quadro de dúvidas e insegurança por parte de alguns moradores na localidade de Carioca, conforme revela o depoimento de P.

Diário de campo, anotações de 9 de maio de 2015. 
Por que eles não mexeram na fazenda do G? Ou do outro lado? Eles falaram que é porque tá no mapa deles. Então o Morro inteiro tá no mapa deles, porque não tem base isso não. Porque todo mundo que conversa com eles fala que tá mexendo com eles [...] falaram que ia dar três hectares ${ }^{7}$.

Em 2014, as Notas Técnicas elaboradas pelo Gesta acerca do empreendimento também sublinharam o receio de alguns comunitários e as pressões exercidas sobre eles:

[...] assim como aconteceu em incursão anterior, presenciamos a chegada de funcionários da prefeitura, que de forma ostensiva adentraram a casa da moradora com quem dialogávamos. Naquele momento, a moradora manifestou seu estranhamento dizendo: ichi! É gente da política! Logo em seguida, um dos funcionários se identificou como pertencendo a Secretaria da Saúde passou a fazer indagações à moradora e também a nós [pesquisadores]. Queria saber o que estávamos fazendo ali [...]. Efetivamente, a grande maioria dos moradores com quem travamos conhecimento não tem se manifestado publicamente sobre os processos de mudança e impactos relacionados aos empreendimentos minerários. Quem geralmente se desloca para participar de audiência e reuniões do COPAM (URC-Jequitinhonha) são lideranças com maior trânsito junto à prefeitura e à empresa Manabi, como vereadores, presidente de sindicato, pastor de igreja evangélica e grande parte dos funcionários públicos municipais (ARAÚJO; OLIVEIRA; ZHOURI, 2014, p. 1, grifo dos autores)

No tocante às dissidências e hesitações quanto ao projeto, foi registrada situação similar no Espírito Santo, na região pretendida para as instalações do porto e do mineroduto. Em especial, na localidade de Entre Rios, interagimos com ribeirinhos que destacaram o conflito vivenciado com a empresa União Engenharia, a qual havia adquirido e cercado áreas ocupadas pelo grupo. Rumores locais sugeriam conexões entre a União e o próprio projeto Manabi. De todo modo, oposições foram declaradas por parte de alguns moradores que pontuaram as tensões no local:

Diário de campo, anotações de setembro de 2014. 
Hoje não tem como sobreviver do mar. A Petrobrás e a Aracruz tiraram nossa pesca [...] você pesca cinco meses e recebe quatro meses, aí vem o aluguel chegando, conta batendo... ele pula lá dentro d'água pra tirar um meio e sai daqui algemado, com a cara na parede feito bandido. A Manabi é mais uma desgraça que vai chegar, não vai ter rio, nem mar pra pescar (Pescadora, moradora de Regência) ${ }^{8}$.

No entanto, os posicionamentos críticos desse grupo são obliterados e não conseguem ascender aos espaços institucionais dominados por representantes e lideranças que integram uma forte rede de assentimento, defesa e mesmo reivindicação do referido projeto. A inexistência de um consenso e de uma disposição contestadora e opositiva mais visível na arena pública nos leva a outra via de análise particularmente interessada nas estratégias corporativas cujas táticas e temporalidades permitiram a consolidação desses posicionamentos de conformidade, legitimação e salvaguarda do projeto associado aos temas progresso, futuro e desenvolvimento, conforme revela o pronunciamento da prefeita de Morro do Pilar:

[...] nós estamos preparados para receber o empreendimento, podem ter certeza disso e quero o apoio de vocês para construir um projeto de mineração diferenciado, verdadeiramente sustentável. Eu entendo as críticas, que a oposição pode existir, mas tem que prevalecer o desejo do povo; eu não estou aqui para representar a minha vontade, eu estou aqui representando a vontade do meu povo (MINAS GERAIS, 2014, grifo nosso).

Chama a atenção nesse caso o processo pelo qual as redes locais de apoio ao empreendimento mobilizam a retórica da escolha e, perversamente, da autodeterminação para reivindicar o "desenvolvimento". Cabe examinar a construção desse imaginário que propugna o projeto de mineração como desejo e intervenção necessária capaz de produzir o bem-estar e a prosperidade da população, colocando em curso uma verdadeira “vontade de progresso" (LI, 2007, p.4).

\footnotetext{
Diário de campo, anotações de 27 de abril de 2015.
} 
Arturo Escobar (2007) utiliza ferramentas foucaultianas para investigar justamente esse aspecto produtivo do desenvolvimento, sua capacidade de integrar, administrar e controlar populações de formas cada vez mais detalhadas e exaustivas. Uma contribuição de Escobar está em mostrar como as categorias sociais do desenvolvimento não são simplesmente impostas, elas circulam de modo complexo, modificando a forma como as pessoas se veem e se orientam. Com efeito, faz-se pertinente a observação de que os desejos, vontades e aspirações da população constituem justamente o objeto e o instrumento da cultura do desenvolvimento, de modo que ela opera, conforme assinala Escobar (2007, p. 93, tradução nossa), "no interior e através das culturas locais".

A ideia de "vontade de progresso" de Li (2007, p. 4) recupera exatamente essa faceta do caráter convocatório da categoria "desenvolvimento". No licenciamento de um grande projeto industrial extrativo, a retórica do desenvolvimento é fundamental porque, enquanto valor, essa categoria possibilita o alinhamento das aspirações locais aos objetivos preconizados pelo projeto. É nesse horizonte que são colocadas em curso tecnologias destinadas a produzir o consentimento e a validação do projeto. Uma importante via de investigação identificada no processo da pesquisa se refere, portanto, ao mapeamento e análise das estratégias corporativas de intervenção sociocultural (ANTONELLI, 2009) gestadas e operacionalizadas no campo da responsabilidade social empresarial (BRONZ, 2011) e da "mineração sustentável" (KIRSCH, 2010, p. 88). A matriz analítica selecionada permite-nos tratar tais estratégias como tecnologias de governo. Para Rose (1998, p. 35), o termo "governo":

[...] não se refere nem às ações de um sujeito político calculador, nem às operações dos mecanismos burocráticos e de administração de pessoal. O termo descreve, em vez disso, uma certa forma de buscar a realização de fins sociais e políticos através da ação, de uma maneira calculada, sobre as forças, atividades e relações dos indivíduos que constituem uma população.

Conforme sublinha Antonelli (2009), as estratégias corporativas de intervenção sociocultural são mecanismos de modulação moral e política da conduta 
que colocam em cena aparatos sociais diversos destinados a inserir as subjetividades nos "cálculos das forças políticas" a partir de, segundo Rose (1998, p. 31), "práticas, instituições e técnicas". É nesse horizonte que se multiplicam técnicas destinadas a fomentar a participação ao mesmo tempo em que mantém sob controle o potencial opositivo e crítico das intervenções a respeito dos empreendimentos (LI, 2007). Como uma "ferramenta preventiva" (BRONZ, 2011, p. 222) que atenua as possibilidades de intervenção opositiva, a "gestão estratégica dos impactos" se transmuta em técnicas destinadas a "interferir na percepção dos atores sobre os efeitos do empreendimento" (BRONZ, 2011, p. 229), transformando as interações e modalidades de diálogo em verdadeiros "instrumento[s] de persuasão" (BRONZ, 2011, p. 231).

No caso Manabi, diversas ações levadas a cabo nesse espírito de "diálogo" e "responsabilidade" podem ser lidas como investimentos antecipatórios e como recurso às tecnologias de participação responsáveis tanto pela institucionalização e ritualização das práticas participativas no licenciamento, quanto pelo esvaziamento de seu potencial político contestatório ou disruptivo. Chamamos de "investimentos antecipatórios" (OLIVEIRA, 2018, p. 170) toda uma gama de ações prévias que correm paralelas ou mesmo à revelia do licenciamento, mas que produzem efeitos sobre este, prevenindo oposições e, conforme destaca Bronz (2011), estabilizando um modelo para as interações empreendedor-atingidos, reduzindo, com efeito, as vias de ação, escolhas e possibilidades colocadas às mobilizações contestadoras. Tais investimentos têm os seguintes objetivos: (a) costurar alianças, sobretudo, junto aos agentes públicos e "atores estratégicos", visando à constituição de uma poderosa rede de influência e opinião dedicada a garantir à viabilização do empreendimento; (b) fomentar expectativas e mesmo a "vontade de progresso", crescimento e geração de emprego junto à população, produzindo a ambiguidade dessas situações em que os atingidos serão também mão de obra (mesmo sob condições precárias e temporárias para os projetos); (c) identificar pontos de tensão e possíveis conflitos emergentes, administrando-os

\footnotetext{
9 Segundo define Bronz (2011, p. 228): “atores estratégicos" são aqueles que podem contribuir para viabilizar a obtenção das licenças, seja por sua localização e pertencimento nos "quadros de poder das políticas de gestão ambiental e territorial da região escolhida", seja porque têm algum potencial de influência e formação de opinião como acadêmicos e organizações com acesso às mídias.
} 
com o auxílio de atores locais entre os quais se destacam lideranças e peritos destinados à pacificação e à desmobilização dos antagonismos, o que inclui o trabalho de advogados, assistentes sociais, psicólogos e cientistas sociais. O objetivo é claramente explicitado no Programa de Comunicação Social (PCS) da Manabi:

[...] o PCS deve atuar [...] com antecipação suficiente para prevenir possíveis conflitos, mapeando dificuldades nas relações entre a empresa e os grupos sociais envolvidos, além de primar pelo princípio da comunicação participativa a serviço das demandas locais, do órgão licenciador e também do empreendimento (ECOLOGY BRASIL; ECONSERVATION, 2013, p. 14, grifo nosso).

O recurso a essas estratégias é, pois, bastante evidente no caso do projeto Manabi em que, à revelia do licenciamento e previamente às audiências públicas e debates para a deliberação das licenças, a empresa deu início a uma série de ações:

(1) Negociações individualizadas junto aos proprietários com intuito de garantir a área necessária ao estabelecimento da faixa de servidão para o mineroduto e a área essencial à instalação do porto.

(2) Estabelecimento de escritórios regionais (em Morro do Pilar e em Linhares), que servem ao propósito de atestar a presença, capacidade, estabilidade e disponibilidade para o diálogo por parte da empresa.

(3) Assinatura de protocolos de intenções e convênios com os estados, municípios e localidades com a oferta de compensações futuras.

(4) No município de Morro de Pilar, onde está prevista a abertura de duas cavas, o empreendedor contratou, três anos antes do início das discussões acerca da deliberação da Licença Prévia, uma equipe especializada em reassentamentos, ironicamente designada "Renascer".

(5) Inversões voluntárias no patrocínio de festividades locais como a celebração ao herói nacional caboclo Bernardo, em Regência, e o campeonato de surf de Linhares, respectivamente nos anos de 2013 e 2015, além do patrocínio para a restauração da cúpula do antigo farol em Regência. 
(6) Programa de Desenvolvimento de Fornecedores realizado, no ano de 2013, em parceria com a Federação das Indústrias do Estado do Espírito Santo.

(7) Investimentos em marketing e em assessoria de imprensa, que resultam em sua constante presença na mídia local, a exemplo dos veículos $A$ Gazeta e A Tribuna, no Estado do Espírito Santo.

(8) Distribuição de benesses que incluem a doação de um trator e uniformes escolares à prefeitura do município de Ferros (MG) e cursos de capacitação em mecânica de motores oferecidos aos pescadores dos municípios de Aracruz (ES) e Linhares (ES). Essas iniciativas procuram atestar e convencer acerca da presença e da disposição indubitável da empresa na promoção do "desenvolvimento local".

(9) Estabelecimento de acordos de compensação junto às associações de pesca e do Programa de Diálogo Social, mantido desde 2011, portanto, três anos antes da concessão da primeira licença ao projeto minerário em novembro de 2014. Nesse programa são relatados trinta encontros "com moradores da região de Morro do Pilar e Linhares" (MANABI, 2013, p. 43). Segundo a própria empresa, os encontros e oficinas promovidos no âmbito deste programa "antecedera as audiências públicas que fazem parte do processo de licenciamento" (MANABI, 2013, p. 43).

(10) Publicação do Relatório de Sustentabilidade Manabi, em 2013, a despeito de não possuir qualquer empreendimento em operação e nem sequer licenças e autorizações relativas ao licenciamento para o início de qualquer intervenção nas áreas a serem afetadas. Em 2014, um novo Relatório de Sustentabilidade foi publicado.

(11) Contratação de contralaudo destinado a contestar a existência de mata atlântica atestada pelo Instituto Prístino (2013) em área pretendida para a abertura das cavas;

(12) Patrocínio de eventos acadêmicos ${ }^{10}$, alguns dos quais envolvem o mesmo profissional contratado para a elaboração do contralaudo mencionado.

\footnotetext{
10 Simpósio Internacional de Ecologia e Conservação, promovido na UFMG em agosto de 2014, e Simpósio Internacional de Ecologia: serviços ecossistêmicos e ambientais, também promovido na UFMG no mesmo ano. Também houve o patrocínio à Expedição de Diagnóstico Científico do Rio Doce, efetuado mediante uma parceria entre profissionais da Universidade Federal do Espírito Santo (Ufes) e a TV Gazeta.
} 
No caso de Manabi, é necessário destacar a dimensão antecipatória de tais estratégias. Nessa medida, a circulação midiática, a convocação dos futuros fornecedores, a costura de acordos de compensação e de "protocolos de intenção", o patrocínio de eventos locais, a promoção de cursos, reuniões e oficinas constituem "tecnologias sociais de prevenção contra mobilizações sociais contrárias” (BRONZ, 2011, p. 213). Argumentamos que tais ações podem ser compreendidas como tecnologias de governo porque se realizam no interior da racionalidade da gestão corporativa dos riscos sociais aos investimentos (PINTO, 2013).

A qualificação "antecipatórios" acentua a natureza estratégica dessas técnicas de gestão dos conflitos sociais, permitindo-nos problematizar seu caráter programático etático (LI, 2007). Portanto, podemos abordar as estratégias corporativas mencionadas como novos investimentos de validação e legitimação. Os esforços dirigidos para tais ações e estratégias apresentam-se, assim, como réplicas calculadas às críticas diversas que a indústria da mineração vem enfrentando desde os anos de 1990 (KIRSCH, 2014). São tentativas de responder e ao mesmo tempo dissolver os conflitos emergentes (LI, 2007), deslocando-se de uma postura defensiva para o ativo engajamento prévio com as demandas e aspirações locais no sentido de obter acordos e consentimentos anteriores à implantação do projeto. Dessa forma, a via de ação frequentemente eleita está baseada no mote de que a "segurança do empreendimento começa nas comunidades" (WELKER, 2009, p. 147, tradução nossa). O resultado é a multiplicação de técnicas que objetivam "cultivar alianças, ganhar acesso territorial e estabelecer linhas de inteligência e comunicação" (WELKER, 2009, p. 147, tradução nossa).

Nesse horizonte, as audiências públicas e, em especial, as reuniões públicas do Copam para apreciação e deliberação das licenças ambientais constituem eventos-chave em que a performance ou dramatização do apoio e defesa do projeto por parte das populações locais são fundamentais para a viabilização dos empreendimentos. A descrição etnográfica inicial apresentada na introdução elucida a mobilização de símbolos (a exemplo das pequenas tranças de taquaraçu fixadas no peito dos apoiadores) e o 
mimetismo de técnicas anteriormente acionadas pelos segmentos que representam uma resistência regional ao projeto, como o uso dos cartões verdes e vermelhos para expressão dos posicionamentos, a despeito do direito à palavra. Já no Espírito Santo, a situação se repete em mobilizações públicas de demonstração de apoio como a coleta de assinaturas para um abaixo-assinado e um protesto designado "Queremos Manabi”, performado em frente à câmara municipal de Linhares (LIDERANÇAS..., 2015). O movimento designado "Queremos Manabi" mantém um perfil na rede social Facebook em que publica frequentemente manifestações de apoio ao empreendimento, divulga informações de encontros e ações do grupo e apresenta vídeos institucionais do empreendedor, além de fotografias das montanhas de papel que constituem o abaixo-assinado. Na página deste perfil, destacam-se as mensagens agressivas e exortativas como: "Linhares quer e não vai ser meia dúzia de pessoas que irão apagar nossos sonhos de uma cidade melhor". Nesse processo, conforme destaca Welker (2009), verdadeiras narrativas morais corporativas são construídas em resposta às táticas e ideias veiculadas pelos críticos, incluindo, sobretudo, ativistas e mobilizações de resistência.

O projeto Manabi é ainda significativo quanto a esses processos, pois a construção da ideia de "mineração sustentável e responsável” depende, nesse caso, da subversão de determinados conhecimentos e memórias da população residente no município vizinho de Conceição do Mato Dentro, afetada pelo projeto similar, designado Minas-Rio, de propriedade da Anglo American. Dessa forma, o Minas-Rio é estrategicamente eleito como contraponto, como "exemplo do desastre" que será evitado pela nova empresa. Ao construir esse contraste, no entanto, as novas narrativas corporativas se apropriam das memórias, das percepções e das experiências locais para constituir e propalar a noção de um empreendimento-modelo em que a Anglo American representa o passado e a Manabi, o futuro. 


\section{CONSIDERAÇÕES FINAIS}

Ao longo do artigo discutimos as estratégias corporativas de engajamento, de administração da crítica e seus possíveis efeitos sobre a dinâmica política dos conflitos (BENSON; KIRSCH, 2010). Conforme argumentamos, o caso Minas-Rio aponta para novas formas institucionalizadas de regulação dos conflitos, modalidades que colocam em curso um efetivo controle sobre a definição de "atingido". Por sua vez, ainda no terreno da análise de sua viabilidade, o caso Manabi nos possibilita refletir sobre as estratégias de intervenção sociocultural (ANTONELLI, 2009) destinadas a produzir adesão, apoio e consentimento dos grupos locais potencialmente afetados pela instalação do projeto.

No caso do Minas-Rio, as estratégias corporativas compreendem negação das denúncias a partir da contratação de laudos alternativos, limitação das responsabilidades em relação aos danos produzidos sobre o abastecimento de água das comunidades, incluindo tentativas de gestão e monopolização sobre a definição de "atingidos", além da promoção de compensações pontuais e restritas, estratégias estas que convergiram, finalmente, para a própria gestão estatal do conflito operada mediante a construção de novas institucionalidades, que intentam operar como verdadeiras "máquinas antipolíticas" (FERGUSON, 2014, p. 256). Em contraste, no caso Manabi, ainda em licenciamento, as táticas envolvem a promoção de engajamentos antecipados que abarcam: a divulgação de "relatórios de sustentabilidade" anteriores à instalação e operação do projeto; a celebração de acordos prévios com as administrações municipais, costurando alianças e redes de apoio e legitimação locais; além da realização de interações prematuras com a população nas localidades, incluindo a abertura de escritórios, acompanhamento psicológico e jurídico, apoio financeiro às festividades locais, oferta de cursos de capacitação e constante merchandising acerca do potencial de geração de empregos. Nesse caso, os efeitos se fazem na produção de práticas de governo gestadas na perversa e confusa mediação dos domínios da violência e do desejo (BAVISKAR, 2003). 


\section{REFERÊNCIAS}

1. ANTONELLI, Mirta A. Minería transnacional y dispositivos de intervención en la cultura: la gestión del paradigma hegemónico de la "minería responsable y desarrollo sustentable”. In: SVAMPA, Maristella; ANTONELLI, Mirta A. (org.). Minería transnacional, narrativas del desarrollo y resistencias sociales. Buenos Aires: Biblos: 2009. p. 51-101.

2. ARAÚJO, Elisa; OLIVEIRA, Raquel; ZHOURI, Andréa. Segunda nota técnica de campo: referente ao processo Supram no 02402/2012/001/2012. Belo Horizonte: Gesta/UFMG, 29 ago. 2014.

3. BAVISKAR, Amita. Between violence and desire: space, power and identity in the making of metropolitan Delhi. International Social Sciences Journal, Hoboken, v. 55, n. 175 , p. 89-98, 2003.

4. BAVISKAR, Amita. Written on the body, written on the land: violence and environmental struggles in central India. Berkeley: University of California, Berkeley, 2001.

5. BECKER, Luzia Costa; PEREIRA, Denise de Castro. O Projeto Minas-Rio e o desafio do desenvolvimento territorial integrado e sustentado: a grande mina em Conceição do Mato Dentro. In: FERNANES, Francisco Rego Chaves; ENRIQUEZ, Maria Amélia Rodrigues da Silva; ALAMINO, Renata de Carvalho Jimenez (org.). Recursos minerais e sustentabilidade territorial. Brasília, DF: CETEM/MCTI, 2011. p. 229-258.

6. BENSON, Peter; KIRSCH, Stuart. Capitalism and politics of resignation. Current Anthropology, Chicago, v. 51, n. 4, p. 459-486, 2010.

7. BRASIL. Ministério Público Federal. Informação técnica elaborada para o Ministério Público Federal, acerca do processo de licenciamento do empreendimento minerário em Conceição do Mato Dentro, MG. Brasília, DF: MPF, nov. 2009.

8. BRASIL. Ministério Público Federal. Informação Técnica n⿳0 05/2010, elaborada para o Ministério Público Federal, acerca do processo de licenciamento do empreendimento minerário em Conceição do Mato Dentro, MG. Ref.: PAC No 1.22.000.000563/2009-21. Brasília, DF: MPF, maio 2010.

9. BRONZ, Deborah. Empreendimentos e empreendedores: formas de gestão, classificações e conflitos a partir do licenciamento ambiental, Brasil, sec. XXI. 2011. Tese (Doutorado em Antropologia Social) - Museu Nacional, Universidade Federal do Rio de Janeiro, Rio de Janeiro, 2011. 
10. DAS, Veena; POOLE, Deborah. El estado y sus márgenes. Revista Académica de Relaciones Internacionales, Madrid, n. 8, p. 19-52, 2008.

11. DIVERSUS. Diagnóstico Socioeconômico da Área Diretamente Afetada e da Área de Influência Direta do empreendimento Anglo Ferrous Minas-Rio Mineração S.A.: (Ex-MMX Minas-Rio Mineração S.A.) - Lavra a Céu Aberto com Tratamento a Úmido Minério de Ferro - Conceição do Mato Dentro, Alvorada de Minas e Dom Joaquim/MG - DNPM No: 830.359/2004 - PA/No. 00472/2007/004/2009 - Classe 06. Belo Horizonte: Diversus, ago. 2011.

12. ECOLOGY BRASIL; ECOCONSERVATION. EIA: estudo de impacto ambiental do Mineroduto Morro do Pilar/MG a Linhares/ES e Porto Norte Capixaba. [S. l.: s. n.], 2013.

13. ESCOBAR, Arturo. La invención del tercer mundo: construcción y deconstrucción del desarrollo. Caracas: El Perro y La Rana, 2007.

14. FERGUSON, James. The Anti-politics machine: development, depoliticization and bureaucratic power in Lesotho. 10. ed. Minneapolis: University of Minnesota Press, 2014.

15. FERREIRA ROCHA. Estudo de atualização das áreas de influência (AI) do projeto Minas-Rio mineração. Belo Horizonte: Ferreira Rocha, 2013.

16. FURBINO, Zulmira. MPs ouvem queixas das comunidades. Estado de Minas, Belo Horizonte, 18 abr. 2012. Disponível em: https://bit.ly/3fyz5qv. Acesso em: 29 maio 2014.

17. GESTA. Mineração em Conceição do Mato Dentro feita pela empresa Anglo Ferrous Minas-Rio SA. In: GESTA. Mapa dos conflitos ambientais em Minas Gerais. Belo Horizonte: Gesta, 2019 Disponível em: https://bit.ly/2ZN981b. Acesso em: 29 jun. 2020.

18. INSTITUTO PRÍSTINO. Laudo técnico sobre a viabilidade ambiental do projeto minerário Morro do Pilar: inquérito civil MPMG no. 0175.12. 000053-4. Belo Horizonte: Instituto Prístino, 2013.

19. KIRSCH, Stuart. Mining capitalism: the relationship between corporations and their critics. Oakland: University of California Press, 2014.

20. KIRSCH, Stuart. Sustainable mining. Dialect Anthropology, New York, v. 34, p. 87-93, 2010.

21. LI, Tania Murray. The will to improve: governmentality, development and the practice of politics. Durham: Duke University Press, 2007.

22. LIDERANÇAS e comunidade fazem protesto 'Queremos Manabi' em Linhares. Linhares em Dia, Linhares, 19 maio 2015. Disponível em: http://linharesemdia. 
com.br/noticias/geral/20407-liderancas-e-comunidade-fazem-protesto-queremosmanabi-em-linhares.html. Acesso em 7 set. 2015.

23. MANABI. Relatório de Sustentabilidade 2013. [S. l.]: Manabi, 2013. Disponível em: https://bit.ly/3hjPoIk. Acesso em: 7 set. 2015.

24. MANABI. Relatório de sustentabilidade 2014. [S. l.]: Manabi, 2014. Disponível em: https://bit.ly/3ePTLZW. Acesso em: 22 set. 2015

25. MINAS GERAIS. Conselho de Política Ambiental de Minas Gerais. Ata da $\mathbf{8 5} \mathbf{a}^{\mathbf{a}}$ reunião extraordinária da URC Jequitinhonha. [S. l.: s. n.], 18 set. 2014.

26. MINAS GERAIS. Conselho de Política Ambiental de Minas Gerais. Ata da $\mathbf{8 8}^{\mathbf{a}}$ reunião extraordinária da URC Jequitinhonha. [S. l.: s. n.], 6 nov. 2014.

27. MINAS GERAIS. Ministério Público. Coordenadoria de Inclusão e Mobilização Sociais. REASA - Rede de Acompanhamento Socioambiental. Belo Horizonte: MP, 2012.

28. MINAS GERAIS. Sistema Estadual de Meio Ambiente. Parecer único Sisema n $^{\circ}$ 001/2008: processo Copam n 0472/2007/001/2007. Belo Horizonte: Sisema, 2008.

29. MINAS GERAIS. Sistema Estadual de Meio Ambiente; ANGLO FERROUS MINAS-RIO MINERAÇÃO. Adendo ao parecer único Sisema 001/2008: P.A. Copam no 472/2007/001/2007. Belo Horizonte: Sisema, 2008.

30. OLIVEIRA, Raquel. O duplo engajamento pesquisa-assessoria: relatos de experiências e alguns desafios. In: LIMA, Antonio Carlos de Souza et al. (org.). A Antropologia e a esfera pública no Brasil: perspectivas e prospectivas sobre a Associação Brasileira de Antropologia em seu $60^{\circ}$ Aniversário. Rio de Janeiro: E-papers, 2018. p. 157-177.

31. PEREIRA, Denise C.; BECKER, Luzia C.; WILDHAGEN, Raquel O. Comunidades atingidas por mineração e violação dos direitos humanos: cenários em Conceição do Mato Dentro. Revista Ética e Filosofia Política, Juiz de Fora, v. 1, n. 16, p. 124-150, 2013.

32. PINTO, Raquel Giffoni. O poder da crítica: um estudo sobre a relação entre empresa e movimentos sociais em um contexto de conflito ambiental. Estudos de Sociologia, Araraquara, v. 18, n. 35, p. 307-324, 2013.

33. PRATES, Clarissa Godinho. Mineração em Conceição do Mato Dentro: uma análise da REASA como instância de 'resolução' de conflito. 2014. Monografia (Graduação em Ciências Socioambientais) - Faculdade de Filosofia e Ciências Humanas, Universidade Federal de Minas Gerais, Belo Horizonte, 2014.

34. PROJETO responsável e solidário. Revista Ecológico, Belo Horizonte, n. 29, 2011. 
35. ROSE, Nikolas. Governando a alma: a formação do eu privado. In: SILVA, Tomas Tadeu da (org.). Liberdades reguladas: a pedagogia construtivista e outras formas de governo do eu. Petrópolis: Vozes, 1998. p. 30-45.

36. SANTOS, Ana Flávia Moreira. Não se pode proibir comprar e vender terra: Terras de ocupação tradicional em contexto de grandes empreendimentos. In: ZHOURI, Andréa; VALENCIO, Norma (org.). Formas de matar, de morrer e de resistir: limites da resolução negociada de conflitos ambientais. Belo Horizonte: Editora UFMG, 2014. p. 143-165.

37. WELKER, Marina. Corporate security begins in the community: mining, the corporate social responsibility industry and environmental advocacy in Indonesia. Cultural Anthropology, Chicago, v. 24, n. 1, p. 142-179, 2009.

38. ZHOURI, Andréa. Mapeando desigualdades ambientais: mineração e desregulação ambiental. In: ZHOURI, Andréa; VALENCIO, Norma (org.). Formas de matar, de morrer e de resistir: limites da resolução negociada de conflitos ambientais. Belo Horizonte: Editora UFMG, 2014. p. 111-141.

39. ZUCARELLI, Marcos Cristiano. A matemática da gestão e a alma lameada: os conflitos da governança no licenciamento do projeto de mineração Minas-Rio e no desastre da Samarco. 2018. Tese (Doutorado em Antropologia) - Universidade Federal de Minas Gerais, Belo Horizonte, 2018.

40. ZUCARELLI, Marcos Cristiano. O papel do termo de ajustamento de conduta no licenciamento ambiental de hidrelétricas. In: ZHOURI, Andréa (org.). As tensões do lugar: hidrelétricas, sujeitos e licenciamento ambiental. Belo Horizonte: Editora UFMG, 2011. p. 151-181. 